\title{
Aplicações Farmacêuticas de Polímeros
}

\author{
Janaina C. 0. Villanova, Rodrigo L. Oréfice \\ Departamento de Engenharia Metalúrgica e de Materiais, UFMG
}

Armando S. Cunha

Departamento de Produtos Farmacêuticos, UFMG

\begin{abstract}
Resumo: Os polímeros representam uma das classes de materiais mais versáteis disponíveis para aplicações em diversas áreas, inclusive a farmacêutica. Polímeros naturais, naturais modificados e sintéticos são empregados como excipientes farmacêuticos para a formulação de cosméticos e medicamentos de liberação convencional e de liberação modificada. Nos dias atuais, polímeros são desenvolvidos para atuarem como moduladores e direcionadores da liberação de fármacos em sítios específicos no organismo. Polímeros biodegradáveis, bioadesivos, biomiméticos e hidrogéis responsivos têm sido amplamente incluídos em formulações farmacêuticas. Os avanços na idealização de novos Sistemas de Liberação de Fármacos somente são e serão permitidos a partir do desenvolvimento de polímeros projetados especificamente para a área farmacêutica. Neste sentido, o presente artigo visa a revisar e apresentar informações sobre o uso de polímeros em aplicações farmacêuticas que poderão ser úteis no planejamento de novos sistemas com desempenhos superiores.
\end{abstract}

Palavras-chave: Biopolímeros, sistemas de liberação de fármacos, excipientes, biomateriais.

\section{Pharmaceutical Applications of Polymers}

Abstract: Polymers are very versatile for a series of applications including pharmaceutical applications. Natural polymers, modified natural polymers and synthetic polymers are employed as excipients in the manufacture of cosmetics and systems for conventional and modified delivery of drugs. More recently, polymers have been developed to be able to modulate and deliver drugs to target places. Biodegradable polymers, bioadhesives, biomimetic materials and responsive hydrogels have been included in pharmaceutical formulations. The advances in the concept of new drug delivery systems will only be possible with the development of polymers specifically designed for the pharmaceutical field. Therefore, this manuscript intends to review and report information regarding the use of polymers in pharmaceutical applications that can be useful in designing new systems with improved performance.

Keywords: Biopolymers, drug delivery systems, excipients, biomaterials.

\section{Introdução}

Os polímeros sintéticos fazem parte do nosso cotidiano e representam uma das classes de materiais mais versáteis que existem, apresentando inúmeras aplicações, entre as quais, no setor farmacêutico ${ }^{[1-5]}$. Dada a relevância dos polímeros na produção de medicamentos e cosméticos, fazse necessário que os Farmacêuticos busquem conhecer um pouco mais sobre estes componentes e, que os Engenheiros de Materiais reconheçam as necessidades específicas do setor. Assim, o objetivo principal deste trabalho é mostrar a amplitude da aplicação dos polímeros na preparação de medicamentos e cosméticos e, a partir da percepção da importância e da contribuição que estes agregam ao desempenho das formulações, pretende-se revelar oportunidades à comunidade científica envolvida com polímeros.

\section{Polímeros em Medicamentos}

No contexto do presente artigo, três termos serão empregados para designar os medicamentos (formas farmacêuticas). São eles: medicamento tradicional (ou convencional), sistema de liberação de fármacos e sistema de liberação de fármacos de desempenho terapêutico avançado. Os dois últimos podem ser considerados inovadores.

Medicamentos tradicionais são caracterizados por apresentarem liberação imediata do fármaco. São consagrados na terapêutica, sendo disponíveis, comercialmente, há vários anos. Do ponto de vista tecnológico, são de fácil preparação, uma vez que sua produção é bem estabelecida, não requerendo componentes e equipamentos sofisticados ${ }^{[4,5]}$.

Por definição, Sistema de Liberação de Fármaco (SLF) ou Drug Delivery System (DDS) é um sistema de administração desenvolvido para prolongar o tempo de liberação do fármaco no organismo, sustentar sua concentração

Autor para correspondência: Rodrigo L. Oréfice, Escola de Engenharia, Bloco 2, Departamento de Engenharia Metalúrgica e de Materiais, sala 2233, Av. Antônio Carlos, 6627, Pampulha, CEP: 31270-901, Belo Horizonte, MG, Brasil. E-mail: rorefice@demet.ufmg.br 
plasmática e controlar a localização temporal e espacial das moléculas in vivo, por meio da aplicação de princípios biológicos e químicos ${ }^{[5]}$. Desta forma, alterações cíclicas na concentração são eliminadas e a disponibilidade biológica do fármaco é aumentada. Também, pode ser conseguida redução da toxicidade, supressão de reações adversas e diminuição do número de doses administradas, diariamente ${ }^{[4-7]}$. Além de apresentarem liberação modificada do fármaco, a fabricação dos SLF's requer, muitas vezes, o emprego de equipamentos, processos e componentes específicos ${ }^{[4,5]}$.

Por último, serão definidos como medicamentos de desempenho terapêutico avançado, aqueles fundamentados em micro e nanotecnologia. Em casos específicos, como no tratamento farmacológico do câncer, na administração de vacinas, na terapia gênica e no tratamento de doenças infecciosas e parasitárias, é preferível o emprego de transportadores capazes de direcionar o fármaco, para que este seja disponibilizado, diretamente, nos órgãos, tecidos e células afetados. O direcionamento proporciona seletividade e menor toxicidade ${ }^{[5]}$. Assim, os polímeros podem ser apresentados conforme o tipo de medicamento no qual são incluídos.

\section{Polímeros em formulações tradicionais}

Polímeros são empregados como excipientes em preparações convencionais de medicamentos e cosméticos. Excipiente é qualquer substância, diferente do fármaco, que tem sua segurança avaliadae, a partir de então, pode ser incluído na forma farmacêutica, com intenções variadas, tais como, auxiliar na preparação; fornecer estabilidade física, química e microbiológica ao produto; melhorar a disponibilidade do ativo no organismo; garantir a aceitabilidade do paciente; e, melhorar ou promover qualquer outro atributo relacionado à segurança e efetividade ${ }^{[8]}$.

Medicamentos sólidos convencionais, como pós, comprimidos e cápsulas, contêm excipientes poliméricos exercendo funções variadas. $\mathrm{O}$ amido, a lactose, o sorbitol, o manitol e a celulose microcristalina são os principais diluentes farmacêutico ${ }^{[8,9]}$.A poli(vinil pirrolidona)(PVP), copolímeros do acetato de vinila e vinil pirrolidona (copovidona), polímeros baseados no ácido acrílico, polissacarídeos e inúmeros derivados da celulose, são utilizados como aglutinantes (agentes utilizados para aumentar a coesão entre os pós e facilitar os processos de granulação e compressão na preparação de comprimidos) ou como desintegrantes (agentes facilitadores da desintegração de comprimidos e cápsulas nos fluidos do estômago), conforme a concentração empregada na formulação ${ }^{[9]}$. Poli(metacrilatos) podem ser usados como aglutinantes em processo de granulação pela via úmida. A poli(acrilina) potássica é um agente desintegrante para cápsulas e comprimidos. A carboximetilcelulose (CMC) sódica reticulada é um desintegrante para a fabricação de cápsulas, comprimidos e grânulos de desintegração rápida $^{[4,5,9]}$.
Outra aplicação para os polímeros em sólidos orais é como agente complexante. Em 1975 o laboratório Sanofi Winthrop lançou o medicamento Kayexalate ${ }^{\circledR}$ - uma resina trocadora de cátions preparada a partir do poliestireno (PS), para administração oral ou retal, em casos de hiperpotassemia. Ao atravessar o trato gastrintestinal, o sódio presente na resina é trocado pelo potássio, reduzindo os níveis deste último ${ }^{[10]}$. Outro exemplo do uso de polímero como complexante é no $\operatorname{RenaGel}^{\circledR}$, um produto obtido a partir de um hidrogel de poli(cloridrato de alilamina), administrado pela via oral, que retira íons fostato do organismo, reduzindo os níveis de fósforo $^{[11]}$.

Os filmes dissolvíveis apresentam desintegração e dissolução rápidas, quando administrados pelas vias bucal, sublingual, oftálmica, vaginal ou tópica. Os polímeros usados na preparação desses filmes são hidrossolúveis, tais como, éteres de celulose, polissacarídeos, poli(álcool vinílico) (PVA), poli(óxido de etileno) (PEO), PVP e copovidona ${ }^{[12]}$.

Outras formas farmacêuticas tradicionais são os cremes, as loções e as pomadas baseadas em sistemas emulsionados. Emulsões farmacêuticas são caracterizadas como sistemas dispersos, constituídos por dois líquidos imiscíveis estabilizados por um agente emulsionante, geralmente, um polímero $^{[4-6]}$. Polímeros e copolímeros acrílicos, combinados ou não com tensoativos iônicos ou não iônicos, formam emulsões estáveis do tipo óleo em água (O/A). Os principais exemplos de emulsificantes poliméricos são copolímeros de elevada massa molar derivados do ácido acrílico e do alquil metacrilato, contendo ligações cruzadas por éteres alílicos do pentaeritritrol ou da alil sacarose $\mathrm{e}^{[9,13,14]}$.

A forma farmacêutica gel, que pode ser definida como uma preparação obtida pela dispersão de polímeros gelificantes - incrementadores de viscosidade - em meio aquoso, é obtida, principalmente, a partir dos polímeros derivados da quitosana, do PEO e dos sais de cálcio e sódio do copolímero metil vinil éter e anidrido maleico ${ }^{[4-6]}$. Contudo, o principal gelificante empregado em medicamentos e cosméticos é o poli(ácido acrílico) (PAA), conhecido como carbômero ${ }^{[4-6,9]}$. Alguns exemplos de preparações comerciais contendo PAA são: os anti-inflamatórios de uso tópico Cataflan ${ }^{\circledR}$ Emulgel e Feldene ${ }^{\circledR} \mathrm{Gel}$; produtos para o tratamento da acne e redução das linhas de expressão, como o Isotrex ${ }^{\circledR} \mathrm{e}$ o Differin $^{\circledR}$; e, o gel Nenê Dent ${ }^{\circledR} \mathrm{N}$, para o alívio dos efeitos decorrentes da primeira dentição.

Polímeros são empregados em medicamentos líquidos (soluções, xaropes e elixires), como solubilizantes e estabilizantes. Estudos recentes mostram que polímeros hidrossolúveis como a gelatina, o PEO, o PVA, a PVP e o poli(etileno glicol) (PEG), inibem, significativamente, o crescimento de cristais de fármacos lipossolúveis em solução ${ }^{[15,16]}$. Fármacos como indometacina, nifedipina e tolbutamida, podem ser estabilizados por polímeros contendo anel pirrolidona, como a PVP e a PVP-co-acetato de vinila. A incorporação do ritonavir, fármaco de solubilidade limitada, 
no PEG-800, pode aumentar a concentração do fármaco no intestino, melhorando sua biodisponibilidade ${ }^{[15-17]}$.

Medicamentos de uso parenteral (injetáveis) contêm polímeros de baixa massa molar, utilizados como solventes, cossolventes e estabilizantes. São exemplos: PEG, PEG 660, PEG monooleato, poli(propileno glicol) (PPG) e diferentes copolímeros baseados no PEO, como os poloxâmeros - copolímeros em bloco do óxido de etileno e óxido de propileno $^{[18,19]}$.

A aplicação dos polímeros na área cosmética vem crescendo à medida que a cosmetologia ganha espaço como ciência. Cadeias poliolefínicas modificadas por derivados acrílicos contendo aminoácidos ou compostos de amônio quaternário originam xampus com boas propriedades ${ }^{[20]}$. $\mathrm{O}$ poli(dialil dimetilamônio) e copolímeros acrílicos, de natureza aniônica e anfotérica, respectivamente, são polímeros usados em condicionadores ${ }^{[21]}$. O copolímero silicone/acetato de vinila é empregado em sprays para cabelo. Monômeros contendo ácido 2-acrilamida-metilpropanosulfônico, previamente neutralizado, quando polimerizados na presença de acrílicos de baixa hidrossolubilidade, originam uma estrutura com maior hidrofobia e compatibilidade com outros componentes lipofílicos, sendo úteis na preparação de emulsões contendo filtros solares. Copolímeros acrílicos baseados no acrilato, metacrilato de amônio e estireno originam máscaras, delineadores, mousses e filtros solares com excelentes características. Poliacrilatos e poliuretanos (PU's) são utilizadas como formadores de filmes em máscaras e maquiagens ${ }^{[22]}$. A Tabela 1 apresenta uma relação dos principais polímeros de uso farmacêutico, descritos no Handbook of Pharmaceutical Excipients ${ }^{[9]}$.

\section{Polímeros em medicamentos inovadores}

\section{Propriedades dos polímeros exploradas em medicamentos inovadores}

$\mathrm{Na}$ maioria das vezes, respostas terapêuticas eficazes e seguras são conseguidas administrando-se medicamentos tradicionais. Outras vezes, o regime terapêutico ideal requer a administração de um sistema de liberação de fármacos e/ou de sistemas de desempenho terapêutico avançado ${ }^{[3-5]}$. Nos medicamentos inovadores, os polímeros são componentes essenciais, já que exercem ação direta na liberação dos fármacos ${ }^{[3,5]}$. Neste contexto, é importante conhecer a terminologia empregada para caracterizar os polímeros, o que pode auxiliar no esclarecimento da aplicabilidade dos materiais em dado sistema de liberação.

Polímeros biodegradáveis podem ser definidos como aqueles que sofrem degradação macromolecular in vivo, por ação de enzimas, micro-organismos ou células ${ }^{[23,24]}$. O termo biodegradação descreve os processos envolvendo quebra de cadeia e modificações da massa molar e da solubilidade do polímero. Processos biológicos, físicos e químicos, podem atuar na biodegradação ${ }^{[25,26]}$.
Polímeros bioadesivos são materiais capazes de se ligarem a substratos biológicos de duas maneiras: aderindo à camada mucosa (mucoadesivos) ou à membrana celular (citoadesivos). A bioadesão é uma propriedade explorada como estratégia para aumentar o tempo de permanência de um medicamento no organismo. Em consequência, a biodisponibilidade dos fármacos pode ser melhorada e o número de doses tomadas, diariamente, pode ser reduzido. Outra vantagem é que a bioadesão pode ser modulada para ocorrer em sítios específicos, diminuindo a toxicidade e aumentando a efetividade terapêutica dos fármacos ${ }^{[27,28]}$.

Os hidrogéis são estruturas poliméricas tridimensionais contendo elevada quantidade de água. São materiais obtidos, normalmente, a partir da copolimerização entre monômeros ou polímeros hidrofílicos com comonômeros polifuncionais, que promovem ligações cruzadas. A presença destas últimas confere aos mesmos a capacidade de absorver grande quantidade de água sem se dissolverem ${ }^{[29]}$. Assim, os hidrogéis podem ser usados na preparação de formas farmacêuticas que permitem a liberação do fármaco após expansão em contato com o meio de dissolução ou em resposta à estímulos fisiológicos como temperatura, $\mathrm{pH}$, enzimas, biomoléculas (glicose, ureia, insulina), força iônica e oxidação ${ }^{[30,31]}$.

Os polímeros ditos bioativos e biomiméticos também vêem sendo pesquisados. Materiais biomiméticos são definidos como aqueles que podem interagir, seletivamente, com o microambiente biológico, mimetizando-o. Já os polímeros bioativos são aqueles capazes de interagir com receptores celulares, via reconhecimento biológico, proporcionando respostas específicas. Poliésteres alifáticos como o poli(hidroxibutirato) (PHB), de origem natural e sintética, têm sido estudados na preparação de materiais biomiméticos ${ }^{[32-35]}$.

Por último, os polímeros terapêuticos são aqueles aos quais são atribuídas propriedades terapêuticas. $\mathrm{O}$ controle da funcionalização e arquitetura de polímeros sintéticos permite que estes se liguem à receptores específicos, presentes em patógenos ou células, promovendo reconhecimento ou comunicação, respectivamente, desencadeando a modulação de respostas inflamatórias, adesão celular ou transdução de sinais. Polímeros contendo fármacos enxertados também são, frequentemente, denominados terapêuticos ${ }^{[3,36,37]}$. Entre as propriedades apresentadas anteriormente, duas merecem destaque: a biodegradação e a bioadesão.

\section{Biodegradação}

A biodegradabilidade dos polímeros é um atributo explorado na modulação da liberação de fármacos, uma vez que é altamente desejável que um material introduzido no organismo desapareça depois de cumprida sua função, sem a necessidade de intervenções para sua retirada. Os produtos de degradação formados são metabolizados a dióxido de carbono e água, via ciclo de Krebs, ou são excretados na urina $^{[23-25]}$. 
Tabela 1. Principais polímeros sintéticos de uso farmacêutico e suas aplicações.

\begin{tabular}{ccc}
\hline Excipiente & Nome comercial & Usos \\
\hline & Acrílicos
\end{tabular}

Poli(acrilina) potássica (polímero derivado do Amberlite ${ }^{\circledR}$ ácido acrílico com divinilbenzeno)

(tipo IRP-88)

Polímero derivado do ácido acrílico reticulado Carbopol $^{\circledR}$ com alilsacarose ou alilpentaeritritrol

Polímero derivado do ácido acrílico reticulado Noveon ${ }^{\circledR}$ AA-1 pelo divinilglicol

Poli(metacrilatos) - polímeros derivados do Eudragit ${ }^{\circledR}$ ácido metacrílico com metacrilto de metila, Plastoid ${ }^{\circledR}$ acrilato de etila, metacrilato de butila, cloridrato de trimetilamôniometacrilato ou dimetilaminometacrilato de etila

Acril-EZE ${ }^{\circledR}$

Stacryl $l^{\circledR}$

Vinílicos

Copolímero do etileno e acetato de vinila

$\operatorname{CoTran}^{\circledR}$

EVA

Polímero derivado do 1-vinil-2-pirrolidona

Kollidon ${ }^{\circledR}$ VA 64

Luviskol ${ }^{\circledast}$ VA

Plasdone ${ }^{\circledR}$ S630

Homopolímero do 1-etenil-2-pirrolidinona PVP

Plasdone $^{\circledR}$

Kollidon ${ }^{\circledR}$

Homopolímero do N-vinil-2-polipirrolidinona

CL

Poli(álcool vinílico)

Elvanol $^{\circledR}$

PVA

Poli(acetoftalato de vinila) (polímero derivado Sureteric ${ }^{\circledR}$ de anidrido ftálico e acetato de vinila)

Opadry ${ }^{\circledR}$ Enteric

Copolímero metil vinil éter e anidrido maléico Gantrez ${ }^{\circledR}$

Ésteres

Poliéster alifático (homopolímero ou Purasorb ${ }^{\circledR}$ copolímero dos ácidos lático, glicólico e Resomer ${ }^{\circledR}$ hidroxicapróico)

Poli(óxido de etileno)

Polioxirano

Copolímero não-iônico em bloco do óxido de Pluronic ${ }^{\circledR}$ etileno e óxido de propileno

Lutrol $^{\circledR}$

Celulósicos

Polímero da hidroxipropilmetil éter de Methocel ${ }^{1 \circledast}$ celulose

HPMC

Hidroxietilcelulose

Cellosize ${ }^{\circledR}$

HEC

Hidroxipropilcelulose
Resina trocadora de íons usada em comprimidos e cápsulas para prolongar a liberação do fármaco, mascarar o sabor e estabilizar o princípio ativo

A principal aplicação é como gelificante, na preparação de géis. Usados como incrementadores da viscosidade em líquidos. Empregados como aglutinante em comprimidos e pellets

Agente bioadesivo - capaz de aumentar o tempo de permanência da forma farmacêutica no organismo. Relatos de usos em preparações vaginais, retais, bucais, tópicas e orais

Exibem funções variadas: estética, organoléptica, estabilizadora, protetora, moduladora da liberação (entérica e sustentada). As vias de administração são oral, bucal, tópica, vaginal e retal

Empregado na fabricação de membranas para sistemas transdérmicos

Agente formador de filme, granulante e aglutinante

Usada como aglutinante, desintegrante e incrementador da dissolução

Utilizada como agente desintegrante para comprimidos

Estabilizante de emulsões e agente de revestimento. Utilizado em formas transdérmicas e oftálmicas

Usado para aumentar viscosidade e como agente de revestimento

Revestimentos entéricos, liberação controlada e sistemas transdérmicos

Material considerado seguro (safe). Biodegradável, utilizado na preparação de SLF's implantáveis e injetáveis

Oxietilênicos

Agente incrementador da viscosidade, aglutinante e mucoadesivo

Poloxâmeros empregados como emulsificantes, solubilizantes e estabilizantes

Incrementadores da viscosidade em preparações oftálmicas. Principal polímero usado matrizes para controlar a liberação de fármacos

As funções principais são como incrementadores da viscosidade e como agentes de revestimento

Desintegrante e aglutinante para sólidos. Membranas para adesivos transdérmicos 
Tabela 1. Continuação...

\begin{tabular}{|c|c|c|}
\hline Excipiente & Nome comercial & Usos \\
\hline Etilcelulose & $\begin{array}{l}\text { Aquacoat }^{\circledR} \text { ECD } \\
\text { Surelease } \\
\text { Ethocel }^{\circledR}\end{array}$ & $\begin{array}{l}\text { Atua como incrementador da viscosidade, como } \\
\text { aglutinante e como modulador da liberação de fármacos }\end{array}$ \\
\hline $\begin{array}{l}\text { Acetoftalato de celulose (polímero do anidrido } \\
\text { ftálico e éster acetato de celulose) }\end{array}$ & Aquacoat $^{\circledR}$ & $\begin{array}{l}\text { Aplicação única como agente de revestimento para } \\
\text { comprimidos, grânulos e pellets }\end{array}$ \\
\hline Carboximetilcelulose & $\begin{array}{l}\text { CMC sódica ou } \\
\text { potássica }\end{array}$ & $\begin{array}{l}\text { Empregada como agenteincrementador da viscosidade, } \\
\text { como aglutinante e como desintegrante em sólidos }\end{array}$ \\
\hline $\begin{array}{l}\text { Acetato de celulose (polímero de celulose } \\
\text { parcialmente acetilado em diferentes graus) }\end{array}$ & Acetato de celulose & $\begin{array}{l}\text { Agente de revestimento para liberação convencional e } \\
\text { modificada de fármacos. Membranas impermeáveis em } \\
\text { sistemas osmóticos (OROS } ®)\end{array}$ \\
\hline
\end{tabular}

Os principais grupos funcionais suscetíveis à hidrólise são os ésteres, orto-ésteres, anidridos, carbonatos, amidas, uretanas e outros. Portanto, podem sofrer biodegradação, via hidrólise química ou enzimática, os poliésteres alifáticos, as poliamidas, os poliuretanas (PU), os poli(orto ésteres), os polianidridos, os polifosfoéteres e as polifosfazonas. Os poliésteres alifáticos são os polímeros que sofrem biodegradação em meio biológico, mais explorados em sistemas de liberação de fármacos. São eles: poli(ácido láctico) PLA, poli(ácido glicólico) PGA, poli(caprolactona) (PCL) e copolímeros dos ácidos lático e glicólico (PLGA) ${ }^{[23-25]}$. Este último, apresenta um menor tempo para completa degradação in vivo, implicando em menor probabilidade de reações adversas, decorrentes, muitas das vezes, de fragmentos cristalinos liberados, cujo tempo de degradação seja excessivamente long ${ }^{[38,39]}$.

Polímeros de origem natural (biopolímeros) são passíveis de degradação in vivo por hidrólise ou ataque enzimático. Os poli(hidroxialcanoatos) - poliésteres de hidroxiácidos (PHAs) - são biopolímeros estereoregulares, opticamente ativos, produzidos por rota biossintética, a partir de fontes naturais. O poli(hidroxibutirato) (PHB) e o copolímero poli(3hidroxibutirato-co-3-hidroxivalerato) têm sido estudados na preparação de sistemas de SLF's. A utilização destes polímeros pode representar um custo menor, quando comparado a outros polímeros biodegradáveis convencionais ${ }^{[40]}$.

A pectina é um polissacarídeo natural resistente à ação das enzimas presentes no estômago e intestino delgado, sendo biodegradada por polissacaridases, enzimas produzidas por bactérias do cólon. SLF's baseados na pectina sofrem erosão no cólon, liberando o fármaco ${ }^{[41-45]}$. Outros polissacarídeos utilizados na preparação de SLF's cólonespecíficos são a quitosana, a goma guar, a amilose, a inulina, a galactomanana, a glucomanana, a xilana e a goma gelana. Todavia, por serem hidrossolúveis, tais polissacarídeos necessitam ser modificados para aumento da hidrofobia, evitando a dissolução prematura dos SLF's ${ }^{[11,42]}$. Polímeros sintéticos contendo ligação azo, como PU's, poliamidas lineares e metacrilatos copolimerizados com a bisacrilamida, que sofrem clivagem por azoredutases presentes no cólon, são úteis na preparação de SLF's para o cólon ${ }^{[46-50]}$.

\section{Bioadesão}

O mecanismo que descreve a bioadesão de polímeros à mucosa ainda não foi totalmente esclarecido. Acreditase que os seguintes eventos estejam envolvidos: adsorção, espalhamento do material bioadesivo sobre a mucosa e interpenetração entre cadeias do polímero e da mucosa ${ }^{[27,28]}$.

De modo geral, as características que favorecem a bioadesividade são: 1 . elevada massa molar; 2 . capacidade de dispersão em água; 3. presença de grande número de grupos carboxila e/ou hidroxila; 4. habilidade de formar ligações de hidrogênio; 5. flexibilidade da cadeia polimérica; e, 6. presença de superfície negativamente carregada, embora alguns polímeros catiônicos sejam bioadesivos. Tais propriedades facilitam a interpenetração das cadeias poliméricas pela mucina, principal proteína do muco, permitindo o estabelecimento de interações físicas e mecânicas ${ }^{[51-55]}$. Um alto conteúdo de carboxilas promove o intumescimento e possibilita a formação de ligações de hidrogênio. Interações dos tipos eletrostática, hidrofóbica e atração de van der Waals, podem ocorrer. $\mathrm{O}$ pH do local, para favorecer a formação de ligações de hidrogênio, deve ser aquele que fornecerá baixa ionização do polímero. Outro importante parâmetro que determinará a bioadesão é o ângulo de contato $(\phi)$ polímero/muco ${ }^{[55,56]}$.

Os principais exemplos de polímeros mucoadesivos são o PAA e a quitosana. Outros são: PEO, PEG, PVP, ésteres de poliglicerol de ácidos graxos (PEGF), poli(lisina), carbômeros, alginato de sódio, goma carragena, sulfato de condroitina, pectina, hidroxipropilmetilcelulose (HPMC) e a CMC. Diferentes moléculas ligantes são imobilizadas covalentemente em polímeros e copolímeros para explorar a bioadesão ou direcionar estas para regiões específicas ${ }^{[57-60]}$. Atenção especial tem sido dada para a preparação de tiômeros através da inclusão de cisteína em polímeros naturais e sintéticos. Os grupos sulfidrila da cisteína interagem com a mucina através de formação direta de ligação dissulfeto ou por oxidação dos grupos sulfidrila. Tiômeros obtidos a partir da imobilização de grupos tióis no PAA, quitosana, hialuronato de sódio e hidroxipropilcelulose, apresentaram capacidade mucoadesiva aumentada ${ }^{[27,61-63]}$.

Uma das primeiras formulações bioadesivas comercializadas foi a ORABASE $^{\circledR}$ - preparada a partir da 
pectina e derivados da celulose, utilizada para incorporação de fármacos administrados na mucosa oral ${ }^{[6]}$. Outros medicamentos bioadesivos, comercialmente disponíveis, são o gel bucal Perioxidin ${ }^{\circledR}$ (Laboratório Gross), empregado no tratamento de doenças periodontais localizadas, e, o Acidform $^{\circledR}$, um gel vaginal capaz de prevenir a gravidez e inibir o desenvolvimento local de patógenos. Tais medicamentos são baseados na hidroxietilcelulose e na goma xantana, respectivamente.

\section{Polímeros em sistemas inovadores de liberação de fármacos}

A seringa pode ser considerada o primeiro SLF da história. A partir dos anos 60 , seringas hipodérmicas feitas de vidro, introduzidas em 1853, começaram a ser substituídas por seringas de plástico. Polímeros empregados na fabricação de seringas devem ser transparentes, apirogênicos, de elevada molhabilidade, com alta estabilidade química e de barreira e, resistentes à esterilização por radiação gama ou óxido de etileno. Por fim, os materiais não devem causar coagulação e reações imunológicas quando em contato com tecidos e fluidos biológicos. Os polímeros usualmente empregados são polipropileno (PP), policarbonato (PC) e copolímeros de olefinas, além de blendas dos mesmos ${ }^{[64,65]}$. Desde então, cada dia são propostos novos sistemas inovadores - baseados em polímeros sintéticos ou naturais, em hidrogéis, em polímeros biodegradáveis ou não, em polímeros bioadesivos, entre outros - visando a liberação de fármacos. Exemplos de SLF's baseados em polímeros são os adesivos, os implantes, os dispositivos médicos e as formas farmacêuticas sólidas matriciais ou reservatórios ${ }^{[5,10,31,66-68]}$. Muitas vezes os sistemas se confundem, e, a divisão apresentada a seguir, é meramente didática.

\section{Sistemas orais de liberação de fármacos}

As cápsulas e comprimidos continuam sendo exaustivamente estudados, pois, apresentam ampla aceitação por médicos e pacientes. Os polímeros são incorporados em tais formas farmacêuticas visando diferentes funções, como mascarar odor e sabor desagradáveis, proteger o fármaco de condições agressivas do meio ambiente (luz e umidade) e do microambiente fisiológico, auxiliar no processo produtivo e para modular a liberação do fármaco ${ }^{[4-7]}$. Genericamente, os medicamentos inovadores orais sólidos podem apresentar liberação retardada ou liberação controlada (prolongada) do fármaco. Estes, por sua vez, podem ser fundamentados em sistemas matriciais, reservatórios, gastrorretensivos, entre outros $^{[5,10,69-71]}$. Cabe ressaltar que, além de sólidos orais, outros medicamentos inovadores baseiam-se em sistemas matriciais e reservatórios ${ }^{[5,10]}$.

\section{Sistemas matriciais}

Os sistemas matriciais podem ser monolíticos (comprimidosoucápsulas)ouparticulados (minicomprimidos, grânulos ou pellets, incorporados em comprimidos ou cápsulas). Tais sistemas podem ser preparados a partir de polímeros solúveis em água, polímeros insolúveis erodíveis ou polímeros insolúveis inertes ${ }^{[4-7,70]}$. Nas matrizes, o fármaco encontra-se disperso no polímero e o controle da liberação pode ocorrer por um ou mais dos seguintes mecanismos: difusão, dissolução, hidratação, precipitação, erosão e/ou degradação ${ }^{[67,70,72-74]}$.

Os principais polímeros naturais utilizados em matrizes são os hidrogéis de quitosana, alginato, sulfato de condroitina, gelatina, dextrina, hialuronana e poli(lisina). Exemplos de polímeros sintéticos são: bisacrilamida, poli(acrilamida) (PAm), PEG, PVA, PAA, poli(ácido metacrílico) (PMAA), poli(acrilato de butila) (PBA), poli(metacrilato de metila) (PMMA), poli(N-isopropil acrilamida), PVP, poli(fosfazona), PLA, PCL, poli(metacrilato de 2-hidroxietila) (PHEMA), poli(oligo(óxido de etileno)monometiléter metacrilato) (POEOMA) contendo ligações cruzadas por grupos tióis e copolímeros diversos ${ }^{[30,75-81]}$. Há um grande número de comprimidos matriciais de liberação modificada comercialmente disponíveis. Na grande maioria, o polímero que controla a liberação é a hidroxipropilmetilcelulose (HPMC).

\section{Sistemas reservatórios}

Nos sistemas reservatórios, a formação de filmes poliméricos sobre os núcleos dos comprimidos fundamentase na evaporação do solvente de um látex polimérico, promovendo a coalescência das partículas e a formação de um revestimento contínuo, que caracteriza-se por ser um filme microporoso ou não poroso. No primeiro caso, a difusão do fármaco determinará o processo de liberação. No segundo caso, a liberação será governada pela erosão/degradação do

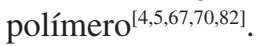

Os ésteres do PAA representam uma classe de polímeros eficazes na preparação de sistemas reservatório ${ }^{[83-85]}$. O PMMA foi o primeiro acrílico empregado como biomaterial, inclusive em processos de revestimento farmacêutico ${ }^{[69]}$. Os principais monômeros utilizados são: metacrilato de metila (MMA), metacrilato de etila (EMA), metacrilato de butila (BMA), acrilato de etila (EA), dimetilaminoetil metacrilato (DMAEMA) e cloridrato de trimetilaminoetil metacrilato $(\mathrm{TAMCl})^{[86-90]}$.

Revestimentos para mascarar sabor e odor desagradável de fármacos podem ser obtidos a partir de copolímeros contendo BMA, MMA e DMAEMA. O copolímero formado é catiônico, interagindo com substâncias ativas aniônicas, neutralizando o sabor das mesmas. Ainda, o revestimento formado é insolúvel em $\mathrm{pH}$ próximo da neutralidade, não sofrendo dissolução no $\mathrm{pH}$ da saliva ( $\mathrm{pH}$ entre 5 e 7) ${ }^{[85]}$.

Revestimentos entéricos, também chamados gastrorresistentes ou enterossolúveis, são copolímeros aniônicos obtidos a partir do AMA e do MMA. Os filmes formados permanecem íntegros no estômago, porém, desintegram-se em valores de $\mathrm{pH}$ maior que 5, liberando o fármaco. Além de melhorar a biodisponibilidade, o 
revestimento protege os fármacos da degradação em ambiente ácido e protege a mucosa do estômago da ação de certos ativos irritantes ${ }^{[82,85,91]}$. Um exemplo de comprimido cujo revestimento tem finalidade protetora é Aspirina ${ }^{\circledR}$ Protect. Já o Asacol $^{\circledR} \mathrm{HD}$, da farmacêutica Procter \& Gamble, possui revestimento cuja finalidade é proteger o fármaco do $\mathrm{pH}$ ácido e promover sua liberação em $\mathrm{pH}$ acima de 7. Ambos são copolímeros do ácido metacrílico e do metacrilato de metila, nas proporções de 1:1 e 1:2, respectivamente ${ }^{[41]}$. Copolímeros neutros preparados a partir do AE, MMA e BMA são insolúveis em água, apresentam baixa permeabilidade e sofrem intumescimento ao longo de todo o trato gastrointestinal (TGI), sendo empregados para a fabricação de sólidos matriciais ou de sistemas revestidos de liberação sustentada ${ }^{[85]}$. A Figura 1 apresenta os principais polímeros utilizados em SLF's que atuam no TGI.

Um sistema reservatório especial foi desenvolvido pela Bayer, sendo conhecido como bomba osmótica - OROS $^{\circledR}$ (Osmotic-controlled Release Oral Systems). O sistema é utilizado na preparação dos comprimidos Adalat ${ }^{\circledR}$ OROS, empregados no tratamento da hipertensão. Nesta tecnologia, uma membrana semipermeável (hidroxipropilcelulose e acetoftalato de celulose) permite a entrada do meio de dissolução na forma farmacêutica que contém polímeros que intumescem (PEO e HPMC). A pressão interna é aumentada mediante expansão dos polímeros hidrofílicos, forçando a saída do fármaco através de um orifício feito a laser $^{[70,92]}$. A
Figura 2 representa os sistemas orais de liberação: matricial, reservatório e bomba osmótica.

\section{Sistema gastrorretensivo}

O desenvolvimento de medicamentos com tempo de retenção gástrica aumentado, denominados gastrorretensivos (GRT's), é outro artifício capaz de incrementar o efeito terapêutico, sobretudo, em casos de absorção no estômago ou na parte proximal do intestino delgado ${ }^{[93]}$. Diferentes mecanismos são empregados na preparação de GRT's. Além da bioadesão, outra tecnologia é a obtenção de sistemas expansíveis, nos quais os polímeros intumescem em contato com o fluido gástrico e aumentam de tamanho, não passando através da válvula terminal do estômago. Sistemas denominados Hidrodinamicamente Balanceados (HBS), baseiam-se em polímeros com capacidade de expansão, associados ou não a excipientes formadores de gás, que, ao expandirem-se, permitem a liberação do fármaco por difusão. $\mathrm{O}$ ar ou gás carbônico incorporado no polímero expandido permitem a flutuação do sistema ${ }^{[5,59,70,93]}$. Os principais polímeros utilizados nos GRT's são gelatina, quitosana, HPMC, alginato de sódio, PAA e copolímeros derivados dos ácidos acrílico e metacrílico ${ }^{[94,95]}$.

\section{Medicamentos implantáveis}

Os implantes representam os SLF's destinados à inserção, de forma invasiva, em tecidos ou órgãos. Entre os anos 60 e 80

Anatomia do trato gastrintestinal com indicações dos SLFs e polímeros que atuam nas respectivas regiões do TGI

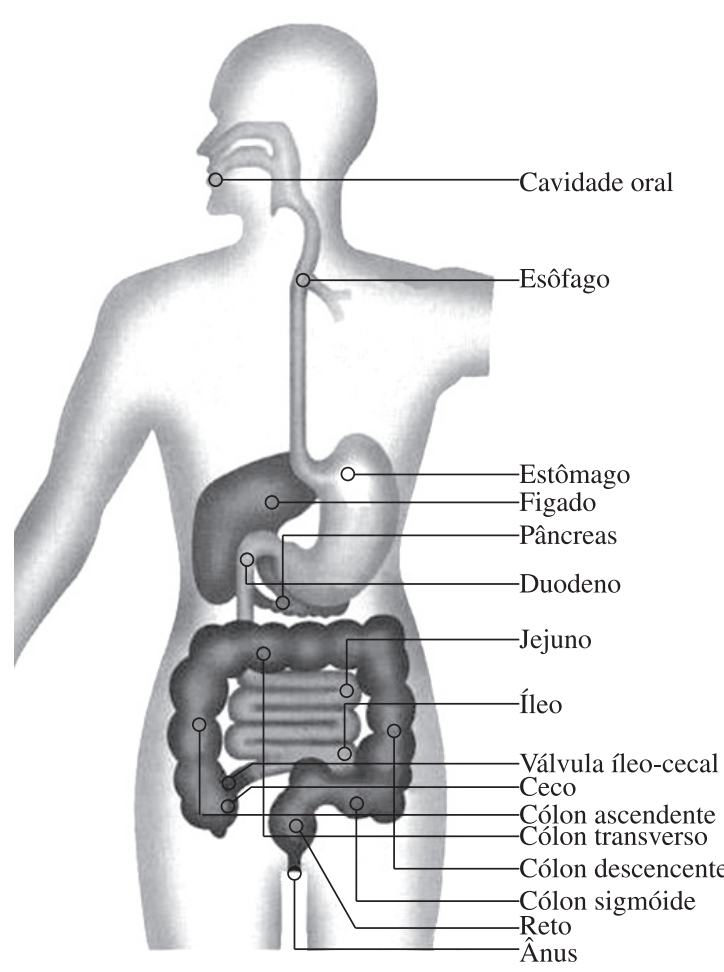

\begin{tabular}{|c|c|c|c|c|}
\hline Região & $\mathrm{pH}$ & $\begin{array}{l}\text { Tempo de } \\
\text { residência }(\mathrm{H})\end{array}$ & SLF & Polímeros \\
\hline Cavidade oral & 6,8 & $\begin{array}{c}\text { Sem } \\
\text { permanência, } \\
\text { exceto para } \\
\text { bioadesivos } \\
\end{array}$ & \begin{tabular}{|c|} 
Filme, adesivo, \\
implante dental \\
$\begin{array}{c}\text { e comprimido } \\
\text { bucal }\end{array}$ \\
\end{tabular} & $\begin{array}{l}\text {-poli(ácido acrílico); } \\
\text {-carbômero; } \\
\text {-PEO; } \\
\text {-tiômeros }\end{array}$ \\
\hline Estômago & $\begin{array}{c}1-3,2 \\
\text { até } 6\end{array}$ & $\begin{array}{l}0-2 \text { (jejum) } \\
3-5 \text { (cheio) }\end{array}$ & \multirow{5}{*}{$\begin{array}{l}\text { Comprimidos e } \\
\text { cápsulas de } \\
\text { liberação } \\
\text { modificada: } \\
\text { retardada e } \\
\text { sustentada. } \\
\text { Sistema: } \\
\text {-matricial; } \\
\text {-resevartório; } \\
\text {-osmótico; } \\
\text {-hidrogel; } \\
\text {-gastroretensivo } \\
\text { (flutuante ou } \\
\text { biodesivo); } \\
\text {-particulado; } \\
\text {-biodegradável }\end{array}$} & \multirow{5}{*}{$\begin{array}{l}\text { Copolímeros } \\
\text { acrílicos: } \\
\text {-AE/MMA; } \\
\text {-AE/MMA/BMA; } \\
\text {-AE/MMA/TAMCl; } \\
\text {-AMA/AE; } \\
\text {-AMA/MMA } \\
\text { Hidrogéis (matrizes) } \\
\text {-PEO; } \\
\text {-PEG; } \\
\text {-PMMA; } \\
\text {-PHEMA; } \\
\text {-PVP } \\
\text { Bioadesivos: } \\
\text {-poli(ácido acrílico); } \\
\text {-carbômero } \\
\text {-PEO; } \\
\text {-PVP; } \\
\text {-tiômeros }\end{array}$} \\
\hline Duodeno & $5-7$ & \multirow{3}{*}{$\begin{array}{c}\text { Variável } \\
\text { entre } 3 \text { e } 6\end{array}$} & & \\
\hline Jejuno & $6-7$ & & & \\
\hline Íleo & $7-7,5$ & & & \\
\hline Cólon & $6-8$ & $\begin{array}{c}\text { Variável até } \\
30\end{array}$ & & \\
\hline Reto & $7-8$ & & $\begin{array}{c}\text { Supositório, gel } \\
\text { e comprimido } \\
\text { bioadesivos }\end{array}$ & $\begin{array}{l}\text {-PEO; } \\
\text {-PEG; } \\
\text {-poli(ácido acrílico) }\end{array}$ \\
\hline
\end{tabular}

Figura 1. Sistemas de liberação de fármacos e polímeros que atuam nas diferentes regiões do trato gastrointestinal (TGI). 

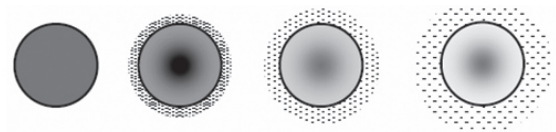

(a)
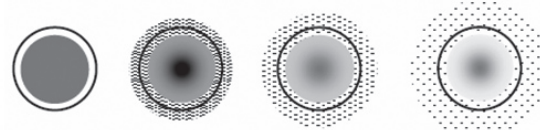

(b)

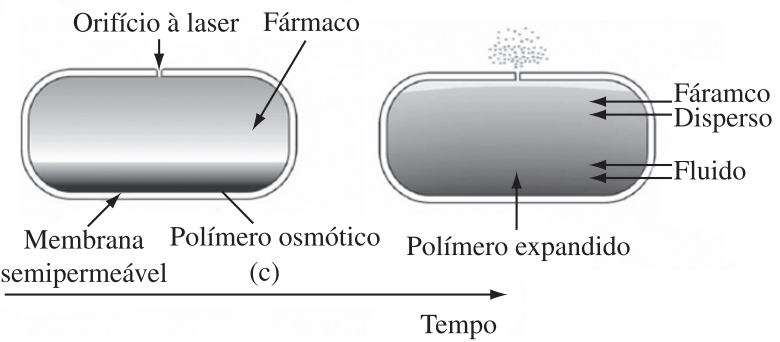

Figura 2. a) Sistema de liberação tipo matricial; b) reservatório; e c) osmótico.

foram desenvolvidos os primeiros sistemas implantáveis para liberação de fármacos. Diversos polímeros, biodegradáveis e não biodegradáveis, são utilizados no preparo de sistemas implantáveis. Os biodegradáveis mais utilizados são o PLA, o PCL e o PLGA. Já o PEVA, o PVA, derivados da celulose, o silicone e polímeros acrílicos são materiais não biodegradáveis, cuja principal desvantagem é a necessidade de remoção posterior ${ }^{[5,10,23]}$.

O Progestasert ${ }^{\circledR}$ - implante intrauterino contendo progesterona - foi lançado pela empresa americana Alza. No Progestesert ${ }^{\circledR}$, a liberação é controlada por membranas não biodegradáveis de poli(etileno-co-acetato de vinila) (PEVA $)^{[10]}$. O Zoladex ${ }^{\circledR}$ LA é um medicamento para implante subcutâneo, contendo o fármaco (acetato de goserelina) disperso em uma matriz de PLGA que, após controlar a liberação do fármaco por 3 meses, é biodegradada e eliminada do organismo ${ }^{[96]}$.

O desenvolvimento de implantes intravítreos merece destaque, pois, além de sustentarem a liberação, reduzem, significativamente, a absorção sistêmica do fármaco administrado pela via oftálmica ${ }^{[97-99]}$. Um implante biodegradável intravítreo contendo dexametasona foi desenvolvido por pesquisadores da Universidade Federal de Minas Gerais. Dados de estudos in vitro mostraram uma liberação de $93 \%$ da dexametasona em 25 semanas. Os estudos pré-clínicos realizados mostraram uma liberação do fármaco, em quantidades adequadas, por um período de 8 semanas. Além disso, alterações nas estruturas oculares e na anatomia da retina não foram notadas durante o período de avaliação ${ }^{[100-102]}$. Em um projeto colaborativo entre os Laboratórios de Tecnologia Farmacêutica e o Laboratório de Engenharia de Polímeros e Compósitos da UFMG, foi desenvolvidoummaterialpoliméricobiodegradável,preparado a partir do PU contendo PCL e/ou PEG. Foram preparados filmes contendo acetato de dexametasona e a liberação do fármaco foi quantificada por cromatografia líquida de alta eficiência. Constatou-se que a taxa de liberação mantevese constante por 53 semanas. Os resultados demonstraram que sistemas PU/PEG/PCL apresentaram taxa de liberação aumentada quando comparado com o PU/PCL ${ }^{[103]}$.

\section{Dispositivos médicos contendo fármacos}

Certos tipos de dispositivos médicos contendo fármacos representam uma tecnologia emergente, explorada pelas áreas médica e farmacêutica. Um dispositivo combinado compreende dois ou mais componentes, química e/ou fisicamente associados ou misturados, que dão origem a uma entidade única. Em outras palavras, são dispositivos médicos que não tem a intenção principal de funcionar como reservatórios de fármacos, mas podem conter estes últimos, visando uma ação farmacológica adjuvante ${ }^{[104-106]}$.

Um exemplo é a incorporação de antibióticos em implantes temporários ou permanentes, na tentativa de reduzir infecções e melhorar a aceitação orgânica do material implantado, minimizando a possibilidade de rejeição ${ }^{[104]}$. O Septopal ${ }^{\circledR}$ (laboratório Merck S.A.) é um dispositivo, comercialmente disponível, apresentado na forma de cordão compostos por esferas de copolímero de metacrilato de metila e acrilato de metila, unidas por fio cirúrgico. As esferas contêm sulfato de gentamicina, um agente antibiótico que pode ser usado no tratamento de infecções de ossos e tecidos moles. As esferas não degradáveis podem ser utilizadas a curto ou longo prazo, sendo removidas manualmente ou através de intervenções cirúrgicas, respectivamente ${ }^{[10]}$. Os stents, utilizados para dilatar a artéria coronária, podem ser recobertos com fármacos antiproliferativos que, ao serem liberados localmente, reduzem a possibilidade de reoclusão e aceleram a revascularização local. O primeiro "stent farmacológico" (drug-eluting stents) foi aprovado para uso pelo Food and Drug Administration (FDA) no ano de $2003^{[104,107]}$.

Outros exemplos de dispositivos contendo fármacos são: implantes ortopédicos, implantes oftálmicos, catéteres venosos e cateteres urinários. Antibióticos, anti-inflamatórios, imunossupressores e antineoplásicos são as principais classes terapêuticas utilizadas na preparação ou recobrimento dos dispositivos poliméricos em questão ${ }^{[104-108]}$.

\section{Medicamentos transdérmicos (adesivos)}

Sistemas Terapêuticos Transdérmicos (STT's) são medicamentos preparados para aplicação sobre a pele, visando ação sistêmica do fármaco, que podem ser apresentados como adesivos (patches) ${ }^{[4-7]}$. De modo geral, os adesivos contêm o fármaco disperso em um reservatório ou em uma matriz. $\mathrm{O}$ sistema é composto por duas camadas poliméricas: a externa, que previne a perda de fármaco e sua exposição ao ambiente e a interna, que controla a liberação. Ainda, pode haver um camada adesiva responsável por fixar o sistema na pele $e^{[5,109]}$.

$\mathrm{O}$ primeiro adesivo desenvolvido e aprovado para uso tópico pelo FDA em 1979 veiculava escopolamina (Transderm-Scop ${ }^{\circledR}$ ), para a prevenção de náuseas e vômitos. O sistema foi preparado a partir do PEVA ou do PP poroso 
e liberava o fármaco por um período de três dias. Nos medicamentos atuais, a liberação pode ser sustentada por até 30 dias. Na preparação de sistemas matriciais, os mais utilizados são o PEG reticulado, poli(2-etil hexil acrilato), PAA, polímeros híbridos baseados em PVP e etilcelulose e HPMC. Em sistemas reservatórios é predominante o uso do PEVA, PU e silicone. Os diferentes polímeros originam membranas conformáveis com diferentes graus de adesividade, transluscência e capacidade oclusiva, além de níveis de transmissão de vapor-d'água e taxa de liberação do fármaco variáveis ${ }^{[110-112]}$.

Adesivos conhecidos como sensíveis à pressão (PressureSensitive Adhesives - PSA's) são materiais especiais utilizados na preparação de patches, uma vez que aderem rápida e permanentemente às superfícies, com uma leve pressão. Nos sistemas transdérmicos, os PAS's são usados para garantir o contato efetivo entre o STT e a área de aplicação, pois, apresentam boas propriedades adesivas inicial e à longo prazo, fácil remoção, flexibilidade, insensibilidade à presença de água e compatibilidade com a pele. Os adesivos sensíveis à pressão são preparados empregando, principalmente, o poli(l-buteno), poliisobutileno, poli(acrilatos), poli(dimetil siloxano) e seus copolímeros ${ }^{[113-115]}$.

\section{Medicamentos de desempenho terapêutico avançado}

Cerca de $40 \%$ das moléculas farmacologicamente ativas descobertas são rejeitadas, devido, principalmente, à reduzida solubilidade e biodisponibilidade. Para contornar tais problemas, carreadores micrométricos e nanométricos, capazes de modularem a liberação com alto grau de reprodutibilidade, surgiram como alternativas eficazes ${ }^{[116-121]}$. Os primeiros medicamentos injetáveis comercializados na forma de microesferas foram o Parlodel $^{\circledR}$ LAR e o Sandostatin ${ }^{\circledR}$ LAR (laboratório Sandoz), ambos baseados em matrizes de PLGA ${ }^{[122]}$.

As nanopartículas poliméricas - nanocápsulas e nanoesferas - são sistemas que apresentam aplicações promissoras, principalmente, na vetorização de anticancerígenos, proteínas, peptídeos, vacinas tumorais e material para terapia gênica administrados pela via parenteral e, também, administração de antibióticos pela via oral ${ }^{[123-126]}$. Os principais polímeros empregados na preparação de nanocarreadores são os naturais modificados, derivados da albumina, colágeno, ácido hialurônico, gelatina, quitosana e alginato, além dos polímeros sintéticos PHEMA, PVA, PAA, PEVA, PEG e a poli(acrilamida). Os nanocarreadores poliméricos biodegradáveis, preparados a partir do PLA, PGA, PLGA, PCL e poli(ortoésteres) têm atraído atenção especial ${ }^{[122,127]}$. A Figura 3 representa, esquematicamente, os principais vetores nanoestruturados baseados em polímeros, estudados na atualidade.

Os conjugados poliméricos são sistemas obtidos pela polimerização direta do polímero e o fármaco, que é liberado após quebra hidrolítica ou enzimática do agregado. Quando a formação do conjugado envolve a presença de ligação

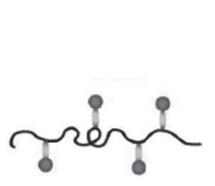

(a)

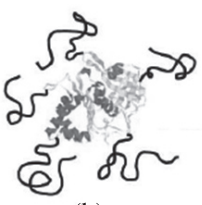

(b)

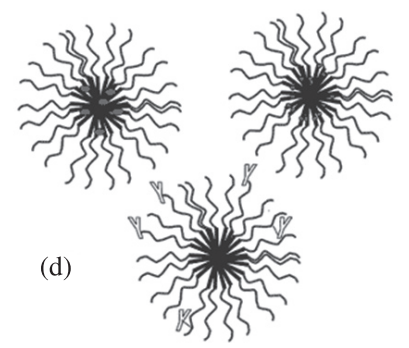

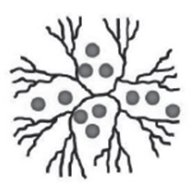

(c)

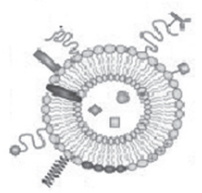

(e)
Figura 3. Sistemas nanoestruturados, micelares e vesiculares: a) conjugados fármaco-polímero; b) conjugados proteína-polímero; c) dendrímeros; d) micelas; e e) lipossomas.

covalente entre o ativo e a matriz polimérica, o sistema é vantajoso para administração parenteral. Já no caso de simples mistura fármaco-polímero, a administração oral é privilegiada. Polímeros como o PEO, PVA, PAM e PLA são usualmente empregados para a preparação de ambos os tipos de sistemas ${ }^{[1,3,36,80,128]}$.

Polímeros dendríticos ou dendrímeros são nanoestruturas formadas pela presença de cadeias e múltiplas ramificações a partir de um núcleo. Possuem arquitetura globular bem definida, massa molar controlada, baixa polidispersividade, valências múltiplas e alto grau de ramificação e funcionalização superficial ${ }^{[122,129-131]}$. Polímeros empregados na preparação de dendrímeros são a poli(amidoamina) (PAMAM), poli(imina propileno) (PPI) e a poli(éter hidroxilamina) (PEHAM) ${ }^{[131-135]}$. O VivaGel ${ }^{\circledR}$ é um gel vaginal microbicida, preparado a partir de dendrímeros baseados na lisina, contendo grupos ácidos sulfônicos superficiais. $O$ medicamento encontra-se na fase II de estudos clínicos e visa o tratamento de doenças sexualmente transmissíveis ${ }^{[132]}$.

As micelas são partículas coloidais esféricas de compostos anfifílicos formadas espontaneamente em solução. São chamadas de sistemas autoestruturados ou self-assemblies. Os sistemas micelares contêm frações dos fármacos covalentemente ligadas ou encapsuladas, cuja principal vantagem é a preparação de medicamentos parenterais contendo ativos de baixa hidrossolubilidade. Existem diferentes tipos de sistemas micelares, entre eles, as micelas propriamente ditas, as vesículas (lipoplexos) e os complexos polieletrolíticos (poliplexos) ${ }^{[136-140]}$.

As micelas poliméricas propriamente ditas são partículas coloidais esféricas com um núcleo hidrofóbico e o exterior hidrofílico. Podem ser caracterizadas como estruturas de copolímeros em bloco montadas sobre um núcleo contendo o fármaco. As micelas podem ter a superfície funcionalizada e responderem a estímulos do ambiente. Polímeros e copolímeros empregados na preparação de micelas são obtidos a partir de PEG, PCL, PLA, poli(histidina), poli(ácido aspártico),poli(isopropilacrilamida), poli(2-etil-2-oxazolina), 
poli(metacrilato de 2-dimetilaminoetila), poli(etileno imina), poli(metacrilato de dimetilamina) e PEOs ${ }^{[127,135]}$.

Os núcleo polieletrolítico ou complexo polieletrolítico pode ser preparado pela deposição camada-a-camada de polímeros sobre um suporte inerte passível de biodegradação. A técnica é baseada na adsorção de espécies carregadas sobre um substrato de carga oposta, alternando as camadas. Carreadores poliméricos hidrofílicos ionizáveis capazes de ligarem-se a biomoléculas de carga oposta são ditos poliplexos $^{[141-143]}$.

\section{Perspectivas Futuras}

Consoante aos requerimentos das indústrias farmacêuticas, os fabricantes de polímeros estão atentos aos fatores que interferem nas decisões de seus clientes. Um importante aspecto é a tendência mundial pela busca de produtos que não causem impacto negativo ao meio ambiente. Neste sentido, esforços têm sido investidos no estudo de dispersões poliméricas aquosas em substituição às orgânicas, para uso farmacêutico. Formulações poliméricas à base de água e polímeros sólidos redispersíveis em água vem ganhando espaço no mercado de excipientes ${ }^{[144-148]}$. Outra perspectiva que tem merecido destaque é a combinação entre polímeros sintéticos e macromoléculas naturais. Estes sistemas apresentam baixa toxicidade, boa estabilidade, baixo custo, biodegradabilidade específica e inúmeras possibilidades de modificações moleculares. Além dos polissacarídeos, blendas de dois ou mais poliésteres biodegradáveis vem ganhando importância ${ }^{[49,50,149-154]}$.

A preparação de polímeros impressos molecularmente (PIM) é uma estratégia promissora na elaboração de matrizes inteligentes para a liberação de fármacos. Os PIM's são obtidos pela formação de um complexo entre monômeros funcionais e o fármaco modelo. A técnica é capaz de produzir polímeros porosos, dotados de sítios específicos de reconhecimento e estereoquimicamente moldados. A liberação do fármaco é modulada em resposta à competição por sítios específicos ou pela presença de íons. Polímeros biomiméticos podem potencializar a interação e a resposta aos estímulos, enquanto a polianilina pode ser usada na otimização da transdução do sinal biomolecular ${ }^{[155-158]}$.

Dispositivos implantáveis, baseados em biossensores e em sensores biomiméticos, acoplados à microcontroladores eletromecânicos, originam sistemas úteis na liberação de insulina em resposta ao aumento do nível de glicose no sangue $^{[155,159-162]}$.

Outra estratégia de interesse é o desenvolvimento de materiais bioadesivos bioinspirados. O modelo de bioadesão observado em mexilhões azuis da espécie Mytilus edulis, por exemplo, surpreende pela elevada capacidade adesiva das proteínas secretadas pela espécie. O fenômeno de adesão nos mexilhões azuis, ao contrário de outras espécies, ocorre tanto em superfícies orgânicas quanto em inorgânicas e em ambientes aquosos e não aquosos ${ }^{[163-167]}$.
Finalmente, as pesquisas apontam para outra inovação: a preparação de excipientes ditos funcionais ou macromoléculas terapêuticas, capazes de otimizar a ação terapêutica de fármacos. O emprego de um medicamento contendo uma galactomanana hidrossolúvel, baseada em manose e galactose, visa aumentar a eficácia e reduzir a toxicidade de quimioterápicos. Grupos específicos presentes no carboidrato ligam-se a receptores sobre-expressados em células tumorais chamados, galectinas, promovendo o transporte de fármacos para o interior do tumor, evitando as células sadias. Estudos clínicos de fase I e II com o medicamento já foram finalizados e os estudos clínicos de fase III encontram-se em estágio $\operatorname{adiantado}^{[168,169]}$.

Para atender aos requerimentos para uso em humanos, a caracterização e o perfil de degradação dos polímeros precisam ser bem estabelecidos. A presença de contaminantes de baixa massa molar, como antioxidantes, estabilizantes, tensoativos, iniciadores e monômeros residuais, pode comprometer a aplicabilidade dos materiais poliméricos na preparação de SLF's. Atenção especial deve ser dada à imunogenicidade do material quando é pretendida a administração do polímero pela via parenteral. Qualquer novo excipiente polimérico desenvolvido, antes de permitida a sua introdução no mercado farmacêutico pelos órgãos regulatórios oficiais, deve ser submetido a várias etapas de aprovação. Além das propriedades físico-químicas, são documentados e avaliados os resultados de: testes toxicológicos (screening toxicológico, citotoxicidade, imunotoxicidade, toxicidade aguda) e parâmetros biológicos como dose eficaz e dose letal média. Portanto, existe um longo caminho a ser percorrido até a comercialização de polímeros idealizados para aplicações farmacêuticas, tornando-se crescente a necessidade de cooperação entre áreas afins no sentido de obter materiais que atendam aos requisitos não somente da engenharia de materiais, mas, aos segmentos médico, odontológico e farmacêutico ${ }^{[170-174]}$.

\section{Agradecimentos}

Os autores agradecem ao CNPq e FAPEMIG pelo apoio financeiro.

\section{Referências Bibliográficas}

1. Langer, R. \& Peppas, N. A. - AIChE J., 49, p.2990 (2003).

2. Oréfice, R. L.; Pereira, M. M. \& Mansur, H. S. "Biomateriais: fundamentos e aplicações", Cultura Médica, São Paulo (2006).

3. Liu, S.; Maheshwari, R. \& Kiick, K. L. - Macromolecules, 42, p.3 (2009).

4. Aulton, M. E. - "Delineamento de formas farmacêuticas", Artmed, Porto Alegre, (2005). 
5. Swarbrick, J. - "Encyclopedia of Pharmaceutical Technology”, Informa Healthcare, England (2007).

6. Allen, L. V.; Popovich, N. G. \& Ansel, H. C. - "Ansel's pharmaceutical dosage forms", Lippincot Williams \& Wilkins, Philadelphia (2005).

7. Gennaro, A. R. - "Remington: the science and practice of pharmacy", Lippincott Williams \& Wilkins, Philadelphia (2005).

8. Villanova, J. C. O. \& Sá, V. R. - "Excipientes: guia prático para padronização", Pharmabooks, São Paulo (2009).

9. AMERICAN PHARMACEUTICAL ASSOCIATION "Handbook Pharmaceutical Excipients", Washington (2006).

10. Hoffman, A. S. - J. Control. Release, 132, p.153 (2008).

11. Slatopolsky, E. A.; Burke S. K. \& Dillon, M. A. - Kidney Int., 55, p.299 (1999).

12. Hariran, M. \& Bogue, A. - Drug Deliv. Technol., 9, p.26 (2009).

13. Valenta, C. \& Auner, B. G. - Eur. J. Pharm. Biopharm., 58, p.279 (2004).

14. Arbós, P.; Wirth M.; Arangoa, M. A.; Gabor, F. \& Irache, J. M. - J. Control. Release, 83, p.321 (2002).

15. Mallick, S.; Pattinaik, S. \&; Swain, K. - Drug Dev. Ind. Pharm., 33, p.865 (2007).

16. Jeong, J. K.; Kim, J. H.; Khang, G. S.; Rhee, J. M. \& Lee, H. B. - J. Kor. Pharmaceut. Sci., 32, p.173 (2002)

17. Tadros, T. - Adv. Colloid Interface Sci., 147, p.281 (2009).

18. Strickley, R. G. - Pharm. Res., 21, p.201 (2004).

19. Date, A. A. \& Nagarsenker, M. S. N - Int. J. Pharm., 355, p.19 (2008).

20. Cincotta, J. J. - Cosmet. Toiletries, 123, p.73 (2008).

21. Leroy, E. - Cosmet. Toiletries, 123, p.53 (2008).

22. Mitarotonda, A.; Benetti, A.; Paganelli, F. \& Galante, Y. M. - Cosmet. Toiletries, 122, p.61 (2007).

23. Barbanti, S. H.; Zavaglia, C. A. C. \& Duek, E. A. R. Polímeros: Ciênc Tecnol., 15, p.13 (2005).

24. Nair, L. S. \& Laurencin, C. T. - Progr. Polymer Sci., 32, p.762 (2007).

25. Kotwal, V. B.; Saifee M.; Inamdar, N. \& Bhise, K. Indian J. Pharmaceut. Sci., 69, p.616 (2007).

26. Healy, K. E. - Curr. Opin. Solid State Mater. Sci., 4, p.381 (1999).

27. Asane, G. S.; Nirmal, S. A.; Rasal, K. B.; Naik, A. A.; Mahadik, M. S. \& Madhusudan Rao, Y - Drug Dev. Ind. Pharm., 34, p.1246 (2008).

28. Andrews, G. P.; Laverty, T. P. \& Jones, D. S. - Eur. J. Pharm. Biopharm., 71, p.505 (2009).

29. Tanaka, Y.; Gong, J. P. \& Osada, Y. - Progr. Polymer Sci., 30, p.1 (2005).
30. Lin, C. \& Metters, A. T. - Adv. Drug Delivery Rev., 58, p.1379 (2006).

31. Pillai, O. \& Panchagnula, R. - Curr. Opin. Chem. Biol., 5, p.447 (2001).

32. Jedliñski, Z.; Kurcok, P.; Adamus, G. \& Juzwa, M. - Acta Biochim. Pol., 47, p.79 (2000).

33. Drotleff, S.; Lungwitz, U.; Breunig, M.; Dennis, A. \& Blunk T. - Eur. J. Pharm. Biopharm., 58, p.385 (2004).

34. Burke, S. A.; Jones, M. R.; Lee, B. P. \& Messersmith, P. B. - Biomed. Mater., 2, p.203 (2007).

35. Börner, H. G. \& Schlaad, H. - Soft Matter, 3, p.394 (2007).

36. Duncan, R. - Nat. Rev. Drug Discovery, 2, p.346 (2003).

37. Kiick, K. L. - Science, 317, p.1182 (2007).

38. Vert, M.; Li, S. M.; Spenhauer, G. \& Guerin, P. - J. Mater. Sci. Mater. Med., 3, p.432 (1992).

39. Motta, A. C. \& Duek, E. A. R. - Revista Matéria, 11, p.340 (2006).

40. Carmigan, F.; Bidone, J. \& Lemos-Senna, E. - Lat. Am. J. Pharm., 27, p.131 (2008).

41. Chourasia, M. K. \& Jain, S. K. - J. Pharm. Pharm. Sci., 6, p.33 (2003).

42. Zhang, Y.; Xie, B. \& Gan, X. - Carbohydr. Polym., 60, p.27 (2005).

43. Freire, A. C.; Podczeck, F.; Sousa, J. \& Veiga, F. - Rev. Bras. Cienc. Farm., 42, p.337 (2006).

44. Covielo, T.; Matricardi, P.; Marianecci, C. \& Alhaique, F. - J. Control. Release, 119, p.2 (2007).

45. Jain, A.; Gupta, Y. \& Jain, S. K. - J. Pharm. Pharm. Sci., 10, p.86 (2007).

46. Guimarães, G. G.; Katsuki, G. I.; Zanardo, N. D.; Ribeiro, D. A. \& Cavalcanti, O. A. - Rev. Bras. Cienc. Farm., 44, p.133 (2008).

47. Monteiro, L. M.; Souza, A. E.; Gianotto, E. A. S.; Nery, M. M. F.; Duarte, J. C.; Freitas, O.; Casagrande, R. \& Baracat, M. M. - Lat. Am. J. Pharm., 26, p.179 (2007).

48. Ravi, V.; Siddaramaiah, T. M. \& Kumar, P. - Indian J. Pharmaceut. Sci., 70, p.111 (2008).

49. Souto-maior, J. P. A. - Int. J. Pharm., 355, p.184 (2008).

50. Souto-maior, J. P. A. - Rev. Bras. Cienc. Farm., 44, p.203 (2008).

51. Thornton, D. J. \& Sheenan, J. K. - Proc. Am. Thorac. Soc., 1, p.54 (2004).

52. Bansil, R. \& Turner, B.S. - Curr. Opin. Colloid Interface Sci., 11, p.164 (2006).

53. Nangia, A. - Pharm. Technol., p.100, 2008. 
54. Linden, S. K.; Sutton, P.; Karlsson, N. G.; Korolik, V. \& McGuckin, M. A. - Mucosal Immunol., 1, p.183 (2008).

55. Harding, S. E. - Biochem. Soc. Trans., 31, p.1036 (2003).

56. Smart, J. D. - Adv. Drug Delivery Rev., 57, p.1556 (2005).

57. Issa, M. M; Köpking-Höggard, M. \& Artursson, P. - Drug Deliv. Technol., 2, p.1 (2005).

58. Shaheen, S. M. - Int. J. Pharm., 2, p.504 (2006).

59. Streubel, A.; Siepmann, J. \& Bodmeier, R. - Curr. Opin. Pharmacol., 6, p.501 (2006).

60. Jones, D. S. - Int. J. Pharm., 374, p.49 (2009).

61. Serra, L.; Doménech, J. \& Peppas, N. A. - Eur. J. Pharm. Biopharm., 71, p.509 (2009).

62. Bernkop-Schnürch, A. - Ad. Drug Delivery Rev., 57, p.1569 (2005).

63. Grabovac, V.; Guggi, D. \& Bernkop-Schnürch, A. - Adv. Drug Delivery Rev., 57, p.1713 (2005).

64. Zelenestkii, V. E. - J. Biomed. Eng., 6, p.91 (1972).

65. Shin, J. Y. - Pure Appl. Chem., 77, p.801 (2005).

66. Kanjickal, D.G. \& Lopina, S. T. - Crit. Rev. Ther. Drug Carrier Syst., 21, p.345 (2004).

67. Lopes, C. M.; Lobo, J. M. \& Costa, P. - Rev. Bras. Cienc. Farm., 41, p.143 (2005).

68. Guse, C. - Int. J. Pharm., 314, p.161 (2006).

69. Uchegbu, I. \& Schatzlein, A. - "Polymers in drug delivery", CRC Press, Boca Raton (2006).

70. Pezzini, B. R.; Silva, M. A. S. \& Ferraz, H. G. - Rev. Bras. Cienc. Farm., 43, p.491 (2007).

71. Waterman, K. C. - Pharmaceut. Dev. Tech., 12, p.1 (2007).

72. Arora, P. \& Tandon, P. N. - Appl. Math. Model., 33, p.692 (2009).

73. Manadas, R.; Pina, M. E. \& Veiga, F. - Rev. Bras. Cienc. Farm., 41, p.143 (2002).

74. Siepmann, J. \& Siepmann, F. - Int. J. Pharm., 364, p.328 (2008).

75. Lee, K. Y. \& Yuk, S. H. - Progr. Polymer Sci., 32, p.669 (2007).

76. Oh, J. K. - J. Am. Chem. Soc., 129, p.5934 (2007).

77. Ahn, S. - Soft Matter, 1, p.1151 (2008).

78. Bajpai, A. K. - Progr. Polymer Sci., 33, p.1088 (2008).

79. Hamidi, M.; Azadi, A. \& Rafiei, P. - Adv. Drug Delivery Rev., 60, p.1638 (2008).

80. Kuckling, D. \& Parrek, P. - Polymer, 49, p.1435 (2008).

81. Xinming, L. - Contact Lens \& Anterior Eye, 31, p.57 (2008).

82. Siepmann, F. - J. Control. Release, 125, p.1 (2008).
83. Kim, S. - Eur. J. Pharm. Biopharm., 71, p.420 (2009).

84. Zalfen, A. M. - Acta Biomater., 4, p.1788 (2008).

85. Dittgen, M.; Durrani, M. \& Lehmann, K. - S. T. P. Pharma Sci., 6, p.403 (1997).

86. Varma, A. J.; Kennedy, J. F. \& Galgali, P. - Carbohydr. Polym., 56, p.429 (2004).

87. Petereit, H. \& Weisbrod, W. - Eur. J. Pharm. Biopharm., 47, p.15 (1999).

88. UNITED STATES PHARMACOPEIA CONVENTION - "National Formulary 25", Rockville (2007).

89. THEEUROPEANDIRECTORATEFORTHEQUALITY OF MEDICINES - "European Pharmacopoeia", Strasburg (2005).

90. HER MAJESTY'S STATIONERY OFFICE - "British Pharmacopoeia", London (2007).

91. Siepmann, F. - Eur. J. Pharm. Biopharm., 68, p.2 (2008).

92. Conley, R.; Gupta, S. K. \& Sathyan, G. - Curr. Med. Res. Opin., 22, p.1879 (2006).

93. Barrocas, P. M. C. - Rev. Bras. Cienc. Farm., 43, p.325 (2007).

94. Kagan, L. - J. Control. Release, 20, p.208, 2006.

95. Garg, R. \& Gupta, G. D. - Trop. J. Pharmaceut. Res., 7, p.1055 (2008).

96. Paterson, W. F. - Arch. Dis. Child., 79, p.323, 1988.

97. Fialho, S. L.; Behar-Cohen, F. \& Silva Cunha, A. - Eur. J. Pharm. Biopharm., 68, p.637 (2008).

98. Ali, Y. \& Lehmussaari, K. - Adv. Drug Delivery Rev., 58, p.1258 (2006).

99. Siqueira, R. C. - Ophthalmol., 220, p.338 (2006).

100. Fialho, S. L. \& Silva Cunha, A - Drug Delivery, 12, p.109 (2005).

101. Fialho, S. L. \& Silva Cunha, A. - Arq. Bras. Oftalmol., 70, p.173 (2007)

102. Fialho, S. L. \& Silva Cunha, A. - Gest. Cienc Saúde, 2, p.47 (2008).

103. Silva, G. - J. Mater. Sci. Mater. Med., 20, p.481 (2009).

104. Woods, T. C. \& Marks, A. R. - Annu. Rev. Med., 1, p.169 (2004).

105. Wu, P. \& Grainger, W. - Biomaterials, 27, p.2450 (2006).

106. Hupcey, M. A. Z. \& Ekins, S. - Drug Discov. Today, 2, p.884 (2007).

107. Venkatraman, S. \& Boey, F. - J. Control. Release, 120, p.149 (2007).

108. Wagh, V. D.; Inamdar, B. \& Samanta, M. K. - Asian J. Pharm. Sci., 2, p.12 (2008). 
109. Bracht, S. - Innovations Pharmaceut. Tech., 5, p.91 (2000).

110. Dimas, D. A. - Pharmaceut. Sci. Tech., 1, p.1 (2000).

111. Kandavilli, S.; Nair, V. \& Panchagnula, R. - Pharm. Technol., 26, p.62 (2002).

112. Prausnitz, M. R.; Mitragroti, S. \& Langer, R. - Nat. Rev., 3, p.115 (2004).

113. Venkatraman, S. \& Gale, R. - Biomaterials, 19, p.1119 (1998).

114. Tan, H. S. \& Pfister, W. R. - Pharm. Sci. Technol. Today, 2, p.60 (1999).

115. Wokovich, A. M. - Eur. J. Pharm. Biopharm., 64, p.1 (2006).

116. Qiu, L. Y. \& Bae, Y. H. - Pharm. Res., 23, p.1 (2006).

117. Langer, R. - Acc. Chem. Res., 33, p.94 (2000).

118. La Van, D. A.; McGuire, T. \& Langer, R. - Nat. Biotechnol., 21, p.1184 (2003).

119. Malmsten, M. - Soft Matter, 2, p.760 (2006).

120. Branco, M. C. \& Schneider, J. P. - Acta Biomater., 5, p.817 (2009)

121. Ganta, S.; Devalapally, H.; Shahiwala, A.; Amiji, M. J. Control. Release, 126, p.187 (2008).

122. Tamilvanan, S. - "Progress in the design of biodegradable polymer-based microspheres for parenteral controlled delivery of therapeutic peptidel protein" in: Pharmaceutical Manufacturing Handbook, Gad, S. C. (ed.), John Wiley \& Sons, New York (2008).

123. Vlerken, L.; Amiji, M. \& Mansoor, M. - Expert Opin. Drug Delivery, 3, p.205 (2006).

124. Filipe, A. C. S. - "Terapia génica para doenças vasculares: desenvolvimento de novos vectores para a entrega intracelular de genes de factores angiogénicos", Tese de Doutorado, Universidade de Coimbra, Portugal (2008).

125. Schaffazick, S. R. - Quim. Nova, 26, p.726 (2003).

126. Bisht, S. - Mol. Cancer Ther., 7, p.3878 (2008).

127. Bawarski, W. E.; Chidlowsky, E.; Bharali, D. J. \& Mousa, S. A. - Nanomed. Nanotechnol. Biol. Med., 4, p.273 (2008).

128. Gavrilin, M. V. - Pharm. Chem. J., 35, p.33 (2001).

129. Svensson, S. - Eur. J. Pharm. Biopharm., 71, p.445 (2009).

130. Esfand, R. \& Tomalia, D. A. - Drug Discov. Today, 6, p.427 (2001).

131. Gillies, E. R. \& Fréchet, J. M. J. - Drug Discov. Today, 10, p.35 (2005).

132. Gong, E. - Antiviral Res., 68, p.139 (2005).

133. McCarthy, T. D. - Mol. Pharmaceutics, 2, p.312 (2005).
134. Svenson, S. \& Tomalia, D. A. - Adv. Drug Delivery Rev., 57, p.210 (2005).

135. Nishiyama, N. - Drug Discov. Today Tech., 2, p.21 (2005).

136. Sivakumar, P. A. \& Rao, K. P. - React. Funct. Polym., 49, p.179 (2001).

137. Torchilin, V. P. - Nat. Rev., 4, p.145 (2005).

138. Immordino, M. L.; Dosio, F. \& Cattel, L. - Int. J. Nanomed., 1, p.297 (2006).

139. Jesorka, A. \& Orwar, O. - Annu. Rev. Anal.Chem., 1, p.801 (2008).

140. Kono, K. - Adv. Drug Delivery Rev., 53, p.307 (2001).

141. Sato, A. - J. Control. Release, 122, p.209 (2007).

142. Miyata, K. - Pharm. Res., 25, p.2924 (2008).

143. De Geest, B. G. - Soft Matter, 5, p.282 (2009).

144. Rios, M. - Pharm. Technol., 6, p.42 (2005).

145. Steward, P. A.; Hearn, J. \& Wilkinson, U. M. C. - Adv. Colloid Interface Sci., 86, p.195 (2000).

146. Bose, S. \& Bogner, R. H. - Pharmaceut. Dev. Tech., 12, p.115 (2007).

147. Cao, X. - Asian J. Pharm. Sci., 2, p.29 (2007).

148. Reyes, Y. - Modell. Simul. Mater. Sci. Eng., 15, p.355 (2007).

149. Guilherme, M. R. - Biomacromolecules, 10, p.190 (2009).

150. Chen, L.; Liu, Z. \& Zhuo, R. - Polymer, 46, p.6274 (2005).

151. Braz, R.; Hechenleitner, A. A. W. \& Cavalcanti, O. A. - Lat. Am. J. Pharm., 26, p.706 (2007).

152. Bunhak, E. J. - Quim. Nova, 30, p.312 (2007).

153. Lao, L. L.; Venkatramann, S. C. \& Peppas, N. A. - Eur. J. Pharm. Biopharm., 70, p.796 (2008).

154. Xu, Z. Molecules, 13, p.490 (2008).

155. Len, G. - Sensor. Actuator. B Chem., 136, p.186 (2009).

156. Bayer, C. L. \& Peppas, N. A. - J. Control. Release, 132, p.216 (2008).

157. Figueiredo, E. C.; Dias, A. C. B. \& Arruda, M. A. Z. Rev. Bras. Cienc. Farm., 44, p.361-375 (2008).

158. Tarley, C. R. T.; Sotomayor, M. D. P. T. \& Kubota, L. T. - Quim. Nova, 28, p.1087 (2005).

159. Laser, D. J. \& Santiago, G. J. - J. Micromechanics Microengineering, 14, p.R35 (2004).

160. Neuse, E. W. - Metal-Based Drugs, 2008, p.19 (2008).

161. Kim, M. S.; Khang, G. \& Lee, H. B. - Progr. Polymer Sci., 33, p.138 (2008). 
162. Lin, G. - Sensor. Actuator. B Chem., 136, p.186 (2009).

163. Lee, B. P.; Huang, K.; Nunalee, N.; Shull, K. R. \& Messersmith, P. B. - J. Biomater. Sci. Polymer Ed., 15, p.449 (2004).

164. Lee, B. P.; Chao, C. Y.; Nunalee, F. N.; Motan, E.; Shull, K. R. \& Messersmith, P. B. - Macromolecules, 39, p.1740 (2006).

165. Lee, H.; Scherer, N. F. \& Messersmith, P. B. - Proc. Natl. Acad. Sci., 103, p.12999 (2006).

166. Lee, H.; Lee, B. P.; \& Messersmith, P. B. LEE. - Nature, 448, p.338 (2006).

167. Sielvermann, H. G. \& Roberto, F. F. - Mar. Biotechnol., 9, p.661 (2007).

168. Zomer, E. - J. Clin. Oncol., 24, p.18 (2006).

169. Tevyashova,A.N.; Olsufyeva,E.N.;Preobrazhenskaya, M. N.; Klyosov, A.; Zomer, E. \& Platt, D. - Russ. J. Bioorg. Chem., 33, p.139 (2007).
170. Pifferi, G. \& Restani, P. - II Farmaco, 58, p.541 (2003).

171. Amidon, G. E.; Peck, G. E.; Block, L. H.; Moreton, R. C.; Katdare, A.; Lafaver R. \& Sheehan, C. - Pharmacop. Forum, 33, p.1311 (2007).

172. Nachaegari, S. K. \& Bansal, A. K. - Pharm. Technol., 28, p.52 (2004).

173. Block, L. H.; Moreton, R. C.; Apte, S. P.; Wendt, R. H.; Munson, E. J.; Creekmore, J. R.; Persaud, I. V.; Sheehan, C. \& Wang, H.- Pharmacop. Forum, 35, p.1026 (2009).

174. Chen, M. - Adv. Drug Delivery Rev., 60, p.768 (2008).

Enviado: 18/08/09 Reenviado: 28/10/09 Aceito: 10/12/09

DOI: $10.1590 /$ S0104-14282010005000009 